\title{
Towards the development of a salinity impact category for South African life cycle assessments: Part 2 - A conceptual multimedia environmental fate and effect model
}

\author{
Tony Leske* and Chris Buckley \\ Pollution Research Group, School of Chemical Engineering, University of Natal, Durban 4041, South Africa
}

\begin{abstract}
In Part 1 of the series, it was shown that there is sufficient justification for the creation of a separate salinity impact category. In this paper, the fundamental basis of environmental life cycle assessments (LCA) is examined. The generalised model, and model simplifications on which the life cycle assessment methodology is based is examined. The formulation of a characterisation model for salinity, which is a local or regional problem, requires the development of environmental fate models. An environmental fate model currently in use to calculate equivalency factors for toxicity effects is evaluated in terms of its applicability for use as is, or in some modified form, to calculate equivalency factors for salinity. It is concluded that this model cannot be used, and a conceptual environmental fate model for salinity is proposed. The proposed conceptual model follows the same approach as models currently in use. It is proposed that a "unit South African catchment" be defined, and that non-steady state hydrological models currently in use in the country be used to predict the fate of salts in the various compartments defined for the "unit catchment".
\end{abstract}

Keywords: environmental life cycle assessment, salinity, characterisation model, environmental fate and effect model, equivalency factors

\section{Introduction}

There are two fundamentally different methodologies for developing methods for LCA. On the one hand, there is the methodology in which comparison of theoretical predictions and actual phenomena provides the benchmark for the adequacy of the LCA theory. A usual approach in this methodology is to analyse the complicated structure in a number of simpler steps. These steps correspond to portions of accepted models, disciplines and causal relationships, such as multi-media fate models. This approach is suitable to change-oriented LCA, where the environmental consequences of different options for fulfilling a certain function are compiled and evaluated. On the other hand, there is descriptive LCA, which is not based on scientific method and cannot be tested empirically. Although there is one ultimate benchmark for testing the predictions of change-oriented LCA, it is clear that this benchmark is useless in practice due to the complicated autonomous developments in society, economy and the environment. The comparison of the predictions of LCA with reality is therefore practically unattainable (Guinee et al., 2000). The predictions made with change-oriented LCA are based on model calculations, and a model is a simplified representation of real mechanisms and phenomena. The choices in modelling are not fully subjective however. Depending on the questions asked, some models are more appropriate than others. It would be best to be as explicit as possible in the assumptions and simplifications that are introduced in modelling the environmental consequences of change.

\section{A general model for LCA}

When studying the change in environmental interventions or effects, it is necessary to specify the time pattern and reference

\footnotetext{
* To whom all correspondence should be addressed.

Present address: Postnet Suite 5, Private Bag X4, Kloof 3610, South Africa

Tึ+2783 6470015; fax: +2731 764 1025; e-mail: Tony.Leske@sappi.com Received 1 July 2003; accepted in revised form 16 January 2004.
}

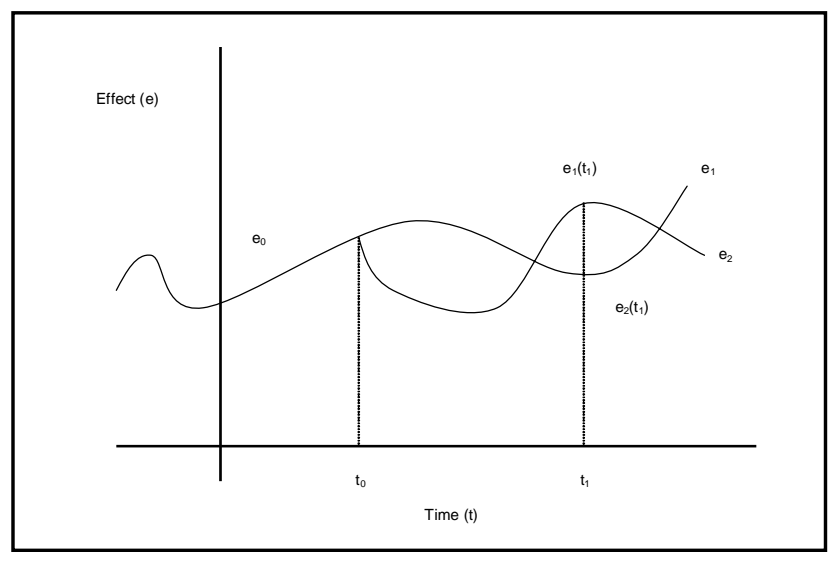

Figure 1

Time pattern of effect (e) before a choice ( $e_{0}$ to the left of $t_{\partial}$ ), after the choice not implemented ( $e_{1}$, to the right of $\left.t_{\partial}\right)$ and after the choice is implemented $\left(e_{2}\right.$, to the right of $t_{\partial}$ ) (adapted from

Guinee et al., 2000)

situation, as shown in Fig. 1.

The LCA analysis is between two parallel systems $\left(\mathrm{e}_{1}\right.$ being the predicted future state without the environmental intervention - or reference situation, and $\mathrm{e}_{2}$ being the predicted future state with the environmental intervention); not a before-after comparison, but a with-and-without comparison.

A general equation for describing the change in environmental effects would include not only time, but also space, as shown in Eq. (1) below:

$$
\Delta_{s, t}=\int_{t_{0}}^{\infty} \iiint_{\text {world }} \int\left[e_{2}(x, y, z, t)-e_{1}(x, y, z, t)\right] d x d y d z d t
$$

Choosing one point in time (e.g. time $\mathrm{t}_{1}$ in Fig. 1) will discard many effects from the life cycle. If all effects over time are required, it is necessary to integrate these over time. In the spatial domain, it is 
theoretically possible to restrict the analysis to one location, modelling of spatial differentiation within a number of regions, or integrating over the entire spatial domain, as shown in Eq. (1).

\section{Model simplifications}

Equation (1) emphasises the basic idea that a full temporal and spatial integration of emissions/effects of pollutants and extraction of resources is idealistically required in LCA methodology. Equation (1) is, however, of little practical use. LCA deals with complex interwoven networks of industrial, agricultural, household and waste management activities. The patterns of these activities are dispersed over many locations and may span decades. The mathematical relationships that describe these real mechanisms are in principle, non-linear, dynamic and will often show hysteresis and irreversibility. No such model of "full reality" exists. Practitioners of LCA are happy if simplifying assumptions are made so that modelling that include the total environmental interventions, integrated over all locations and infinite time in an assumed steady state can be done with reasonable accuracy. The omission of economic mechanisms and spatial detail leads to great simplification, but reduces the quality of the results of the analysis. The inherent simplifications in Eq. (1) are:

- Omission of spatial detail. For example, emissions in the vicinity of different types of ecosystems are not distinguished from one another. This does not mean that distances between unit processes are set equal to zero, but only that transport is taken into account. It also does not mean that all unit processes are assumed to operate according to the technological state that is representative of one region. We may still distinguish between emission characteristics for electricity production at different places. However, we do not specify where the emissions occur. The only default spatial details that are kept are those along a short list of environmental media: air, surface water, soil, sea and sediment. The implicit value judgement made in the spatial integration step is, however, that similar effects in different places count the same in the ultimate evaluation of effects. The reliability and validity of LCA results may be much improved by the introduction of further spatial differentiation. Although space specific data will almost never be available for all processes within the product life cycle, a space-specific assessment may be preferable for those processes for which the required information is available. In order to make spatial differentiation generally applicable to any process in a product life cycle, spatially specific equivalency factors are needed. This has not yet been achieved.

- Omission of temporal detail. This means that emissions are specified as total (infinite) time-integrated emissions.

- Omission of non-linearities. This means, for example, that when the production of $1 \mathrm{~kg}$ of steel is associated with an emission of $5 \mathrm{~kg}$ of a substance, the production of $2 \mathrm{~kg}$ of steel will result in the emission of $10 \mathrm{~kg}$ of that substance.

Multimedia fate models in risk assessment relate continuous emission fluxes to environmental concentrations. Since multimedia fate models depend on geographical and climatological parameters, it is almost impossible to use these without applying some form of spatial differentiation. The use of single values for such parameters may lead to large deviations. Spatial differentiation with respect to fate comes down to the further division of each media into a number of different compartments. All these compartments together compose the so-called unit world. The spatially non-differentiated unit world consists of a small number of homogeneously mixed media, and the spatially differentiated unit world consists of a larger number of homogeneously mixed compartments.

The default simplification of full space and time integration results in no information on spatial and temporal detail being available in the model. One only specifies the total life cycle loadings, in the form of aggregated amounts of releases. Hence any attempt to interpret the contribution of these substances to environmental impact categories, such as ecotoxicity and acidification, can only be made without incorporating spatial and temporal details.

In LCA, it is the capacity of causing harmful effects that forms the basis for the assessment, and not so much the extent to which this capacity has become effective. If we move away from full space and time integration to add more details with respect to spatial and temporal characteristics of release and receiving environment, then we are entering the area of actual impacts, as opposed to potential impacts. In general, for an assessment in completely potential terms, it suffices to use a smaller number of model parameters. For an assessment in completely actual terms, a larger number of parameters are required (Guinee et al., 2000).

The normal current practice of LCA remains placing the emphasis on completeness rather than elaborateness of mechanisms.

\section{Exposure and effect}

An exposure (or intake) factor is a parameter that relates a standard (time-integrated) amount of a substance in a single environmental medium or compartment to the relative amount of this substance that eventually becomes bioavailable for organisms in this medium or compartment. "Exposure" in LCA terminology thus means a discrete event caused by a discrete (mass-loading) emission in LCA. Exposure is also a collective, rather than individual measure. If the population exposed is doubled, the exposure itself is considered to be doubled as well.

An effect factor is a parameter that relates a standard exposure level of a species or ecosystem to a certain effect level. Sensitivity, the presence of sensitive species and background concentrations are all effect-related aspects. The concept of sensitivity is strongly connected to dose-response relationship. A numerical representation of sensitivity may be based either on the exposure value at which a species starts to show adverse effects to a substance (e.g. no effect concentration) or on the relative size of the response to a standard increase of the dose in the response area. Both the noeffect levels and the slope of the dose-response curve vary between species and substances. Since dose-response relationships are seldom linear and homogeneous, the dose-response ratio is not independent of background concentrations. In regions of low background concentrations, effects may not occur, despite the presence of sensitive species. It is a matter of choice whether the purely potential effects in such "below threshold" areas are taken into account, especially for naturally occurring substances such as minerals, which may even be benevolent at low concentrations.

\section{Linking fate and exposure}

Steady-state environmental fate models, based on the theoretical principles outlined and applying the simplifying assumptions discussed above, are used to estimate a fate, or persistency factor. For a continuous emission $E$ (in $\mathrm{kg} / \mathrm{y}$ ) into an environmental compartment, the fate model is used to estimate the concentration of the pollutant in the compartment (Predicted Environmental Concentrations, $\boldsymbol{P E C}$ in $\mathrm{kg} / \mathrm{m}^{3}$ ). The Fate Factor (in $\mathrm{y} / \mathrm{m}^{3}$ ) is given by: 


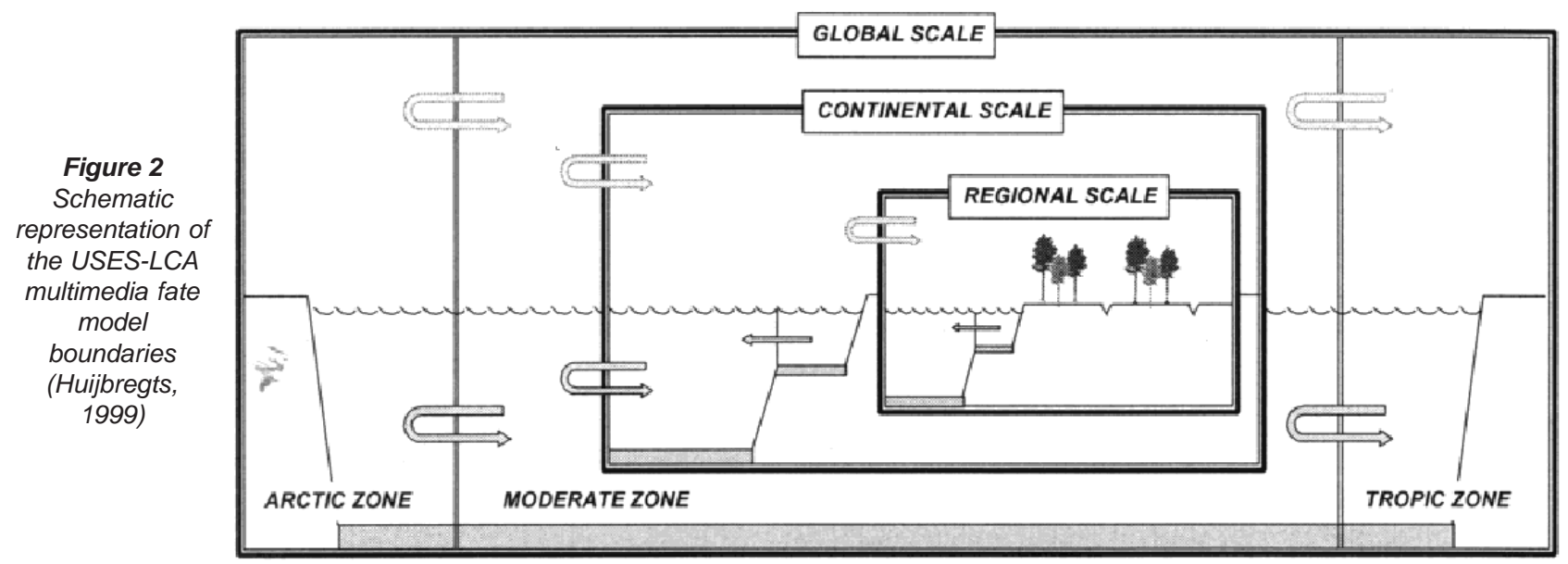

TABLE 1

Substance independent model parameters used in USES-LCA (Huijbregts, 1999)

- Areas of all scales/zones

- Volume fraction of water in plant roots

- Bulk density of plant leaves

- Human intake of drinking water

- Human intake of leaf crops

- Human intake of meat

- Human inhalation rate

- Human soil ingestion

- Temperatures at all interfaces

- Fraction of solids, air, water and organic carbon in suspended matter, sediments and soil

- Fraction of sediment that is aerated

- Wind speeds at all scales

- Average daily precipitation at all scales

- Fraction of all scales that are fresh water, seawater, natural soil, agricultural soil and industrial soil

- Suspended solids concentration in water

- Settling velocity of suspended matter

- Fraction rain water that infiltrates soil
- Volume fraction of fat in plant roots

- Bulk density of plant roots

- Compartment pHs

- Human intake of fish

- Human intake of root crops

- Human intake of dairy products

- Human body weight

- Density of air, water and solid phase

- Surface area of aerosols

- Concentration of Oh radicals in atmosphere

- Atmospheric mixing heights

- Aerosol deposition velocities and collection efficiencies at all scales

- Concentration of biota in water in all scales

- Water depth at all scales

- Sediment mixing depth at all scales

- Generation rate of suspended matter

- Soil erosion rates

- Mass transfer coefficients salinity would be to examine existing models, specifically to determine their applicability to being used as is, or modified, to characterise salinity effects. Several multimedia fate and effect models are available, such as EUSES 2.0 (EC, 1996), CalTox and USES-LCA (Huijbregts, 1999). The USES-LCA model is based on the USES 2.0 model and is the most recently developed model, and is considered by some to be best practice for characterisation of toxicity (Guinee et al., 2000). For this reason, the USES-LCA model

$$
\text { Fate Factor }=\frac{P E C}{E}
$$

The Effect Factor (in $\mathrm{m}^{3} / \mathrm{kg}$ ) is given by:

$$
\text { Effect Factor }=\frac{1}{P N E C}
$$

where:

PNEC is the predicted no effect concentration (in $\mathrm{kg} / \mathrm{m}^{3}$ ).

The product of the Fate Factor and the Effect Factor is called the equivalency factor. The environmental impact due to the activity being assessed is then the product of the Fate Factor, Effect Factor and the mass emitted (taken from the life cycle inventory). Environmental fate and exposure models used to calculate equivalency factors are called characterisation models, and are reviewed in more detail below.

\section{Fate and exposure models}

A good starting point in developing a characterisation model for has been evaluated in some detail below.

In the USES-LCA model, the globe is modelled as a closed system, as shown in Fig. 2. The globe has five spatial scales, which are regional, continental and global, consisting of three parts, reflecting arctic, moderate and tropic geographic zones of the northern hemisphere. The regional and continental scales consist of six compartments each: air, fresh water, seawater, natural soil, agricultural soil and industrial soil. All three climate zones of the global scale consist of three compartments each: air, water and soil.

The model is used to calculate the predicted environmental concentrations of the substance in each compartment of each scale by using the substance-independent data shown in Table 1 and substance dependent data shown in Table 2.

Table 3 shows the environmental mechanisms accounted for in the USES-LCA model to predict movement of pollutants between compartments and scales/zones and hence Predicted Environmental Concentrations in the various compartments at all scales.

$$
\text { WeightedRCR } R_{i, x, e}=\frac{\left(P E C_{i, x, e, c / s}\right) W_{i, c / s}}{P N E C_{x, c}}
$$


TABLE 2

Substance-dependent model parameters used in USES-LCA (Huijbregts, 1999)

- Oral human limit value $\quad$ - Inhalatory human limit value

- Aquatic predicted no effect concentration - Terrestrial predicted no effect concentration

- Molecular weight - Melting point

- Partitioning coefficients - Bioconcentration factors, biotransfer factors and human bioavailability factors

\begin{tabular}{|c|c|c|c|}
\hline \multicolumn{4}{|c|}{$\begin{array}{c}\text { TABLE } 3 \\
\text { Environmental mechanisms modelled by USES-LCA (Huijbregts, 1999) }\end{array}$} \\
\hline \multirow{2}{*}{ Compartment } & \multicolumn{3}{|c|}{ Mechanism } \\
\hline & Advective & Diffusive & Reactive \\
\hline \multirow[t]{2}{*}{ Air } & $\begin{array}{l}\text { Flow (based on wind speed and } \\
\text { pollutant concentration) }\end{array}$ & $\begin{array}{l}\text { Adsorption by water and soil } \\
\text { from air }\end{array}$ & $\begin{array}{l}\text { Degradation due to photo- } \\
\text { chemical reactions }\end{array}$ \\
\hline & Aerosol deposition & $\begin{array}{l}\text { Volatilisation into air from water } \\
\text { and soil }\end{array}$ & \\
\hline \multirow[t]{2}{*}{ Water } & $\begin{array}{l}\text { Flow (based on water flow and } \\
\text { pollutant concentration) }\end{array}$ & Volatilisation into air & $\begin{array}{l}\text { Degradation due to hydrolysis, } \\
\text { photolysis and biodegradation }\end{array}$ \\
\hline & Runoff & Desorption from sediment to water & \\
\hline \multirow[t]{3}{*}{ Soil } & Deposition onto soil from air & Volatilisation to air from soil & $\begin{array}{l}\text { Degradation due to hydrolysis and } \\
\text { biodegradation }\end{array}$ \\
\hline & Erosion & Adsorption by soil from air & \\
\hline & Leaching & & \\
\hline \multirow[t]{2}{*}{ Sediment } & $\begin{array}{l}\text { Sedimentation and re-suspension } \\
\text { from and to water }\end{array}$ & Adsorption from water & $\begin{array}{l}\text { Degradation by hydrolysis and bio- } \\
\text { degradation }\end{array}$ \\
\hline & Burial & Desorption to water & \\
\hline
\end{tabular}

where:

i denotes the impact category

$\mathrm{x}$ denotes the substance

c denotes the environmental compartment

$\mathrm{s}$ denotes the scale.

$\mathrm{W}_{\mathrm{i}, \mathrm{c} / \mathrm{s}}$ are impact-specific weighting factors for compartments

(c) or scales (s).

Weighting factors are based on population densities and compartment masses or volumes, and are used to aggregate the RCRs on different geographical scales per impact category. The Predicted No Effect Concentrations (PNECs) are obtained from toxicological information. The equivalency factors used in the characterisation stage of life cycle assessments are calculated as follows:

$$
E Q_{x, e}=\frac{\text { WeightedRCR }}{\text { Weighted }\left(R C R_{x, c, e}\right)_{\text {reference }}}
$$

where Weighted $\left(R C R_{x, c, e}\right)_{\text {reference }}$ is the weighted risk characterisation ratio for a reference substance (usually 1,4- dichlorobenzene).

Weighted Risk Characterisation Ratios (RCR) are calculated for each environmental compartment as follows:

\section{Limitations of USES-LCA in terms of salinity effects}

In the context of LCA, salinity effects have been defined as those effects caused by elevated (above natural background levels) concentrations of common inorganic ions (particularly sodium, calcium, magnesium, chloride, sulphate and bicarbonate). Toxic effects caused by ions at low concentrations (for example, heavy metals) are therefore not considered to be salinity effects. The major categories of salinity effects are (Leske and Buckley, 2003):

- Material damage (scaling, corrosion, product quality changes)

- Aesthetic effects (taste)

- Aquatic ecosystem effects (chronic and acute effects on individual species, communities and/or ecological processes)

- Terrestrial ecosystem effects (chronic and acute effects on terrestrial animals, change in soil structure and loss of crop yield)

The limitations of current toxicity characterisation models have been well documented (Van Beelen, 1998, Huijbregts, 1999). However, in terms of salinity effects, the following limitations are of particular importance:

\section{Spatial differentiation}

Since multi-media fate models depend on geographical and climatological parameters, it is almost impossible to use them without applying some form of spatial differentiation. In the USESLCA model, equivalency factors are relevant to Western Europe, 
and values at other locations may differ by orders of magnitude. The reliability and validity of LCA results may be much improved by the introduction of further spatial differentiation, to calculate spatially specific equivalency factors (Guinee et al., 2000). This is particularly valid for salinity effects. Salinity is not a global problem, but is, in general, limited to industrialised countries that are arid or semi-arid, such as Australia and South Africa. Salinity problems within a country are furthermore generally limited to specific catchments where industrialisation has taken place to a significant degree, or where extensive irrigation takes place. Salination (as defined) is furthermore limited to terrestrial and fresh water aquatic environments. In terms of salinity effects, the sea can be seen as an infinite sink of common ions.

Idealistically, salinity potentials could be calculated for each catchment in an area or country where salinity effects are significant. This would require detailed data (fate model parameters) for each catchment, and would require that the spatial distribution of life cycle inventory emissions be known, which is most often not the case. A compromise is therefore required between more relevant and reliable LCA results from characterisation models using a high degree of spatial differentiation (with associated high data demand), and less relevant and reliable LCA results from characterisation models using a lower degree of spatial differentiation.

\section{Salinity impacts}

The USES-LCA model calculates six toxicity potentials; fresh water ecotoxicity, marine ecotoxicity, fresh water sediment ecotoxicity, marine sediment ecotoxicity, terrestrial ecotoxicity and human toxicity, for release of emissions into five possible initial release compartments; air, fresh water, sea water, agricultural soil and industrial soil. In terms of the toxicity effects of salinity it may therefore be possible to account for salinity effects. However, salinity (as defined) impacts do not only include ion specific toxic effects, but also include other effects such as crop yield loss, and aesthetic and material damage.

\section{Subsurface water modelling}

Existing toxicity characterisation models make use of very simple rainfall-runoff relationships to estimate the steady state concentrations of sub-substance water. The lack of an adequate subsurface modelling component in the USES-LCA model has been identified as a limitation (Huijbregts, 1999). Adequate modelling of the subsurface water component is critical when evaluating salinity impacts because the salt concentration of subsurface water has a direct influence on crop production, and also has a direct influence on surface water salt concentration, which in turn affects many of the other salinity subimpacts. Published data on threshold salt concentrations, and yield loss as a function of salt concentration are available, and in order to calculate realistic effects potentials, subsurface salt concentrations should be calculated with a corresponding degree of accuracy and scientific relevance.

\section{lonising substances}

Models such as USES and USES-LCA were designed to evaluate the risks of neutral organic compounds, where the toxicity, risk of bioaccumulation and partitioning of the compound between solid and aqueous phase can be estimated from the octanol/water partitioning coefficient of these compounds. These estimations are only valid for neutral organic compounds showing baseline toxicity but not for other types of compounds like organic cations, anions, surfactants and inorganic compounds (Van Beelen, 1998). Although these models have been used to estimate toxicity potentials for some metals (particularly heavy metals), they have not been used to calculate potentials for common ions such as sodium, calcium, magnesium, chloride, sulphate and carbonate/bicarbonate.

\section{Conclusions}

The USES-LCA characterisation model was evaluated in terms of its applicability to be used as a basis for incorporating salinity into the LCA methodology. The USES-LCA model was chosen because it is a well developed and accepted environmental fate model that has been adapted to calculate toxicity potentials for LCA and, intuitively, would seem to be suited to be used for calculating salinity effects, some of which are toxicological in nature. It is however concluded that the USES-LCA model is not suitable for the calculation of salinity potentials. The reasons are discussed in detail above, but in summary, are:

- In the USES-LCA model the globe is modelled as a closed system using a series of nestled multi-media fate models on different geographical scales, with Western Europe being defined as the smallest regional (or "starting") scale. Substance independent model parameters used may result in equivalency factors that are therefore not necessarily valid to South African conditions. Furthermore, salination is a local or regional problem, and a higher degree of accuracy is required in modelling on a smaller spatial scale.

- Although the USES-LCA model accounts for some of the salinity impacts, it does not account for all.

- Sub-surface water and solute transport modelling in the USESLCA model is inadequate for the degree of accuracy and relevance needed to account for salinity effects.

- Perhaps the biggest obstacle in using the USES-LCA model in some modified form to account for salinity effects is that it had been developed to handle organic compounds, and is not suited for estimating the fate of ionic compounds.

\section{A conceptual multimedia fate and effect model for South Africa}

\section{General considerations}

\section{Salinity impacts}

Conceptually, it is proposed that the salinity characterisation model be as all-inclusive as data availability and modelling constraints allow. Salinity effects were discussed in Part 1 of the series (Leske and Buckley, 2003), and in the light of the availability of no-effect concentration data it is proposed that the following effects be accounted for in the methodology:

- Aquatic ecotoxicity effects

- Effects on agricultural crop production

- Material damage effects

- Aesthetic effects

- Effects on livestock

- Effects on natural vegetation

- Effects on natural terrestrial ecosystems.

\section{Spatial differentiation and extent}

In general, multi-media fate models have been developed for the globe as a closed system. Multi-media fate models however depend on geographical and climatological parameters, and it is almost impossible to use them without applying some form of spatial differentiation. It appears to be the general consensus that the reliability and validity of LCA results may be much improved by the introduction of further spatial differentiation (Guinee et al., 
2000; Potting and Hauschild, 1997a and 1997b, Sleeswijk and Heijungs, 1996, Huijbregts, 1998). This is particularly valid for salinity effects. Salinity is not a global problem but is, in general, limited to industrialised countries that are arid or semi-arid, such as Australia and South Africa. Salinity problems within a country are furthermore generally limited to specific catchments where industrialisation has taken place to a significant degree, or where extensive irrigation takes place. Salination is furthermore limited to terrestrial and fresh-water aquatic environments. In terms of salinity effects, the sea can be seen as an infinite sink of common ions.

Idealistically, salinity potentials could be calculated for each catchment in an area or country where salinity effects are significant. This would require detailed data (fate model parameters) for each catchment, and would require that the spatial distribution of life cycle inventory emissions be known, which is most often not the case. A compromise is therefore required between more relevant and reliable LCA results from characterisation models using a high degree of spatial differentiation (with associated high data demand), and less relevant and reliable LCA results from characterisation models using a lower degree of spatial differentiation. It is therefore proposed that, as a starting point, an environmental fate and effect model be developed on a South African scale. This model would have to account for movement of salts across natural and political borders.

\section{Compartments}

Most multi-media fate models include, at a minimum air, soil and water compartments for estimating the ultimate fate of compounds in the environment (Mackay, 1991). In the USES (Guinee et al., 1996) and USES-LCA (Huijbregts, 1999) models the water compartment is further sub-divided into fresh water and seawater. The soil compartment is divided into industrial, natural and agricultural in the USES model, and into industrial and agricultural soil in the USES-LCA model. Some models include a sediment model, sometimes consisting of natural sediment and marine sediment components.

In considering compartmentalisation of the environment, the potential effects of salinity need to be considered. Arguably the highest potential impact of salinity is on agriculture, particularly on irrigated crops. Salt levels in agricultural soils are higher than natural soils due not only to the concentration effects of evaporation, but also due to the application of salts in the form of inorganic fertilisers. It is therefore essential that a distinction be made between natural soil and agricultural soil. In South Africa, most water users (including domestic, industrial and agricultural) use surface water. The agricultural sector is the biggest user of groundwater. It is estimated that $78 \%$ of all groundwater abstracted is used for irrigation, $7 \%$ for rural purposes and $6 \%$ for stock watering. Only $4 \%$ of groundwater abstracted is used in the urban environment. Approximately $16 \%$ of irrigated lands use groundwater (Conrad et al., 1999). The flow and quality of surface water is in turn influenced by the flow and quality of groundwater. It is therefore unavoidable, and in fact desirable (due to the use of groundwater, particularly in the agricultural sector of South Africa), to include a groundwater compartment, also subdivided into natural and agricultural components. The generation of salt (aeolian, terrestrial or aquatic) and the deposition of aeolian salt, and the storage and removal of salt from surfaces are influenced to a large degree by land-use practices. It is therefore proposed that a further subdivision into urban and rural (natural and agricultural) components be made. It is also proposed that sediment be included in the model only as far as it affects the transport of sorbed salt, including transport via eroded sediments from surfaces, and via bed and suspended load in rivers. The sea can be considered as an infinite sink of salts, and is therefore not included in the model.

\section{Components and mechanisms}

Numerous hydrosalinity models have been developed and applied to various studies of South African catchments. These range from simple models requiring very few input parameters to complex three-dimensional groundwater and solute transport models that require a large number of input parameters (Hughes, 1997). It is proposed that a hydro-salinity model be developed based on the rainfall-runoff model originally developed by Pitman (1973) and later expanded to include salinity by Herold, 1981). The Pitman model has become the most widely used rainfall-runoff model in South Africa. The current official version is referred to as WRSM90, and is used to model rainfall-runoff in all catchments within South Africa to the quaternary level. Monthly rainfall and evaporation data as well as simulated river flows and model parameters are therefore available for all catchments in the country (Midgely et al., 1994).

The environmental mechanisms included in the USES-LCA model are given in Table 2.10. For salinity, as defined (Leske and Buckley, 2003), common ions comprise sodium, calcium, magnesium, chloride sulphate and bicarbonate. Collectively, these components are defined (in the context of this study) as total dissolved salts (TDS). It is proposed that in this study TDS be modelled as a lumped parameter, for the following reasons:

- There are more data available on the effects of salinity expressed as a function of TDS, than there are expressed as a function of the concentrations of individual ions.

- There are more surface and groundwater quality data available as TDS (or electrical conductivity, which is a linear function of TDS) than there are of individual ions.

- The availability of models as described above.

Modelling of TDS as a lumped parameter does, however, present certain challenges, particularly with respect to parameters such as solubility limits and adsorption constants.

The major physical and chemical mechanisms that may influence the fate of dissolved salts are briefly described below, and are shown schematically in Fig. 3.

Atmosphere: Marine and/or terrestrial aerosols (a fraction of which will be in a form that will dissolve in water) are transported into, across and out of the air space over South Africa by advection. During this process, additional aerosol mass may be generated, either naturally or due to the activities of man. These aerosols are dispersed into the air space, but are generally limited in their vertical extent of dispersion by stable inversion layers. Deposition of aerosols occur through several mechanisms; wet deposition is the removal of aerosols by rainfall, either in-cloud or below cloud scavenging; dry deposition is the deposition of gases and particles from the atmosphere by processes other than dissolution in rain, cloud or fog.

Surfaces: Salt is generated on urban and agricultural surfaces from anthropogenic activities. This salt is either discharged into the air (as mentioned above), discharged into surface water or onto soils. On impervious areas some or all of the salt deposited from the atmosphere is washed off via surface runoff and generally enters surface water. In pervious areas, some or all of the salt deposited via deposition or discharged by man enters the surface water via 


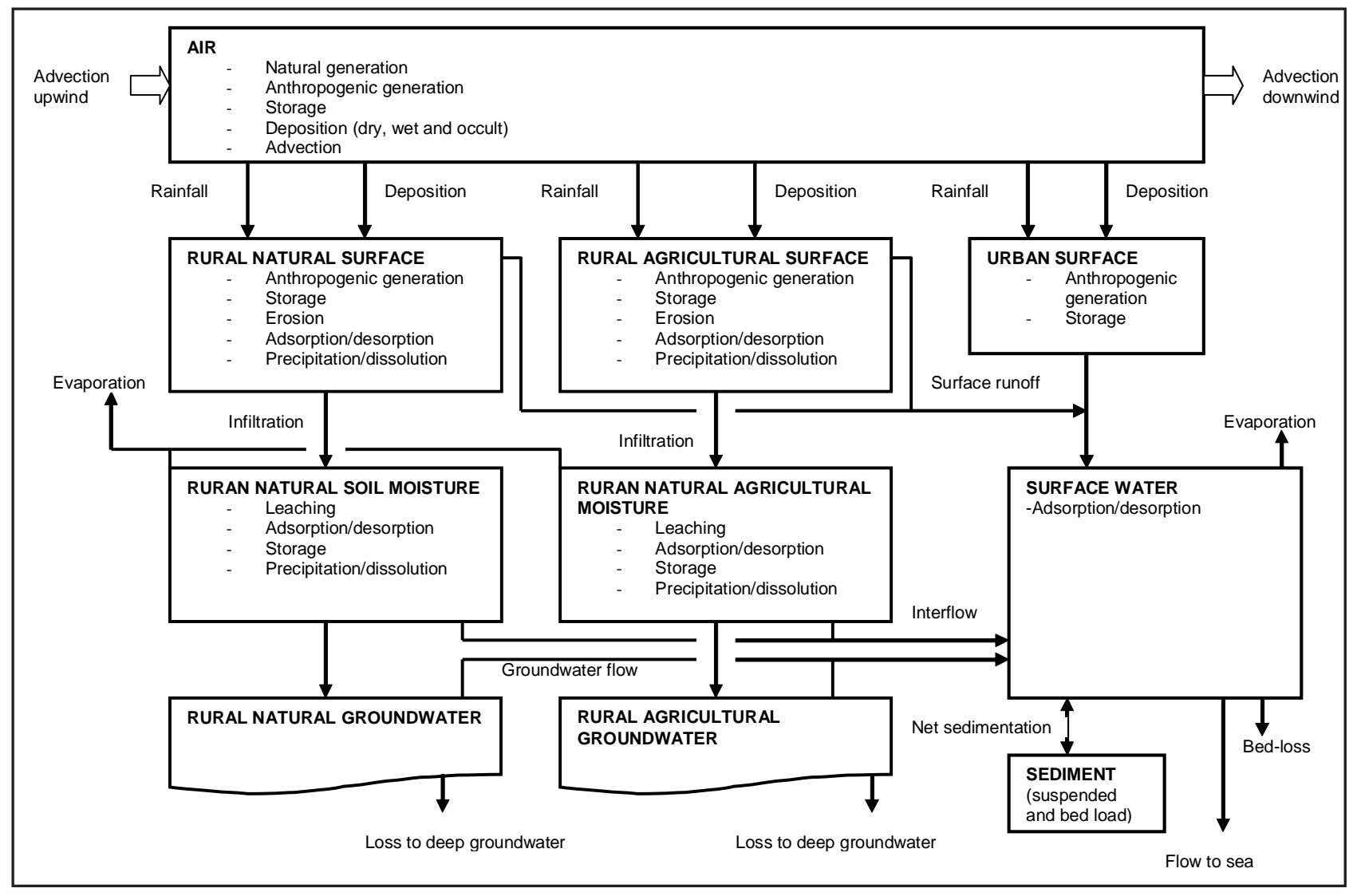

Figure 3

Schematic diagram of the conceptual fate model

surface runoff and the balance enters the soil via infiltration. During rainfall events, erosion takes place, and a small fraction of the salt will adsorb onto the eroded soil that enters the surface water. In the case of irrigated surfaces, additional salt load is applied to the surface from the salts present in the surface water.

Soil and soil water: A number of processes occur in the soil. Depending on the amount of water entering the root zone, the amount of evapotranspiration occurring, and on the soil characteristics, some of the water will be stored in the root zone, some will move towards the surface water as interflow, and some will percolate into the groundwater. Inorganic ions will be generated through the process of leaching. Adsorption and ion exchange will occur between the soil matrix and the soil water, and if sufficient water is lost by means of evapotranspiration, the solubility limit of certain salts may be exceeded and these will precipitate out in the soil matrix, and will re-dissolve if sufficient water becomes available.

Groundwater: Groundwater is either stored (accumulates), enters the surface water as base-flow, or enters deep-seated groundwater. The mechanisms that govern solute transport in groundwater are the same as for soil water.

Surface water: Surface water flow is made up of a surface runoff component, an interflow component and a groundwater flow component. Evaporation from the surface water occurs, and a small fraction of water is lost as bed-loss. In addition to the liquid phase, sediment is transported either as suspended sediment or as bed load. This sediment will contain adsorbed salt.

\section{Conceptual environmental fate model}

\section{The "unit South African catchment"}

It is proposed that the same approach be adopted as was adopted in the USES-LCA model where a "unit environment" was defined. The difference, however, is that a "unit South African catchment" is defined, as shown schematically in Fig. 4. This is a hypothetical catchment (including the air space above it) that has the same surface area as the surface area of the country, but has one single river with a flow equal to the sum of the flows of all rivers in the country and a salt load equal to the sum of the salt loads of all rivers in the country. The land use distribution remains unchanged from actual practices, but is confined to one single urban area, one single rural natural area and one single rural agricultural area. Rainfall on and evaporation from this catchment occur at average rates for the country. It is proposed that the data available in the WR90 series of reports published by the Water Research Commission (Midgley et al., 1994) be used to determine the monthly average flow of the "unit river", the monthly average evaporation for the country, and the monthly average rainfall.

The large existing database of surface water quality in South African rivers can be used to calculate the monthly average of dissolved salt concentration in the "unit South African river".

\section{Atmospheric deposition model}

It is proposed that a simple atmospheric deposition model be developed that could be used to calculate salt deposition rates at a daily time step, without resorting to complex air dispersion mod- 


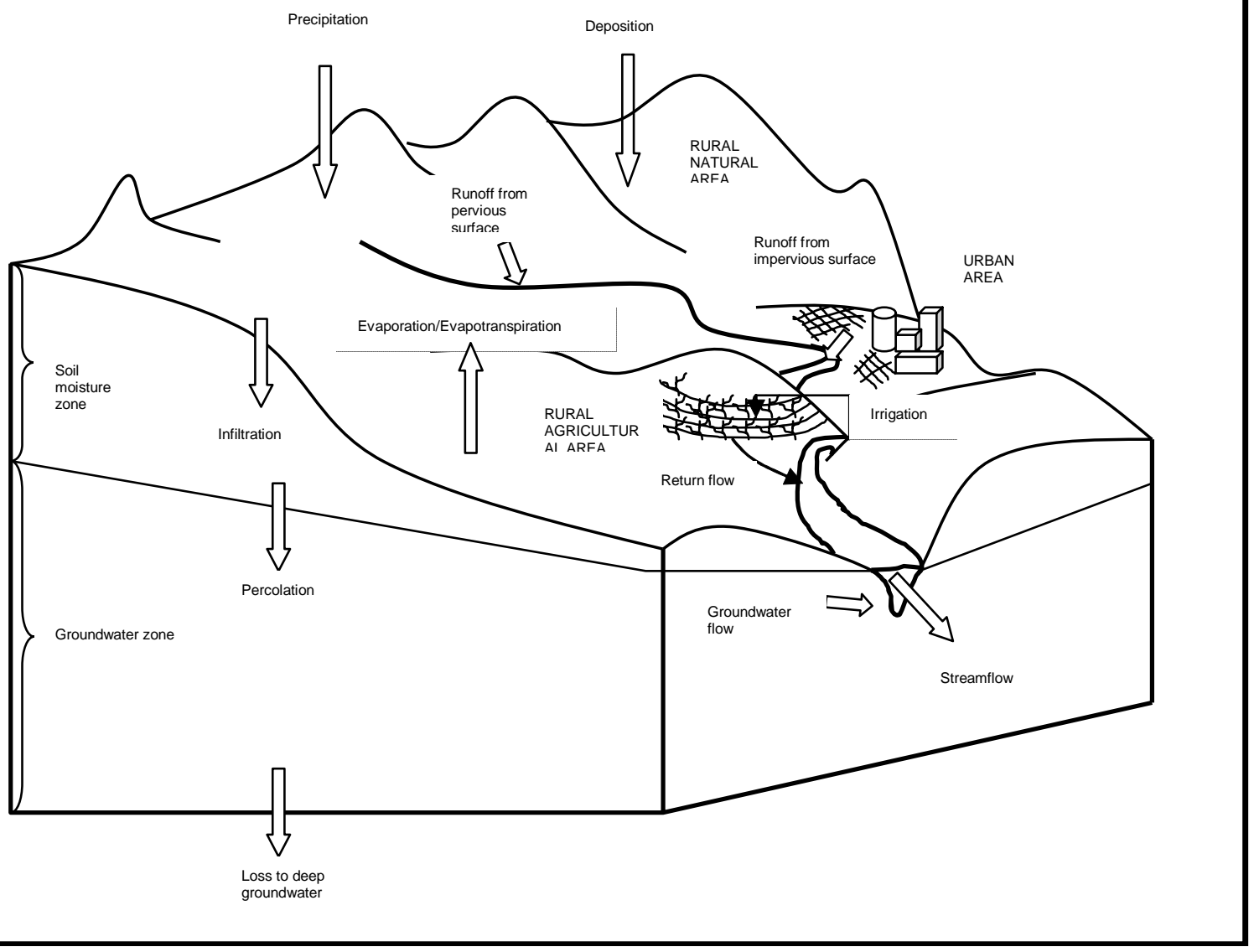

Figure 4

Schematic diagram of the "unit South African catchment"

elling, with its associated data demand. The seasonal variations in salt deposition rates, and the influence of rainfall on salt deposition should be taken into account. The concentration per se of common inorganic salts in the atmosphere does not play a significant role in the salinity impacts as defined. The rate at which these salts are removed from the atmosphere and deposited onto rural and urban surfaces does, however, have a significant influence on salinity impacts.

The objectives of the model are therefore to:

- Improve on the methods used in available characterisation models for estimating atmospheric deposition. In the USESLCA model (Huijbregts, 1999), for example, the volumetric airflow entering the regional air volume is calculated from an annual average wind velocity $(3 \mathrm{~m} / \mathrm{s})$ and the regional air cross-sectional area. Total aerosol deposition is calculated as the sum of dry aerosol deposition and washout. Dry deposition is calculated by multiplying an annual average aerosol deposition rate $(0.1 \mathrm{~cm} / \mathrm{sec})$ with the assumed fraction of chemical associated with the aerosol. Washout is calculated by multiplying the average annual rainfall (700 $\mathrm{mm} /$ year) with a scavenger ratio (100 000).

- To calculate salt deposition rates on rural and urban surfaces at a daily time-step. Calculated deposition rates should be in the same order of magnitude as published values.

- To incorporate the major transport processes occurring in the atmosphere, particularly with regard to processes that influence the fate of salts in other compartments.
Conceptually, a simple box model could be developed that uses average wind speeds to advect aerosols over the catchment (De Nevers, 1995). The movement of aerosols over Southern Africa has been well researched, and some data are available to validate such a model (Swap et al., 1996). Simple models have also been developed to estimate aerosol removal processes (wet, dry and occult deposition), and some model parameters are available for South African conditions (Herold et al., 2001).

\section{Hydrosalinity model}

To calculate salinity equivalency factors, the hydrosalinity model must be able to predict the salt concentrations in the soil and surface water compartments. To do this, a rainfall-runoff model is required that can predict the soil moisture and groundwater profiles as well as the surface water flow.

It is proposed that a hydro-salinity model be developed based on the rainfall-runoff model originally developed by Pitman (1973) and later expanded to include salinity by Herold (1981). The Pitman model has become one of the most widely used rainfallrunoff models in South Africa. The current official version is referred to as WRSM90, and is used to model rainfall-runoff in all catchments within South Africa to the quaternary level. Monthly rainfall and evaporation data as well as simulated river flows and model parameters are therefore available for all catchments in the country (Midgley et al., 1994). It is proposed that the WRSM90 model be used to simulate rainfall-runoff relationships in the "unit South African catchment”, and that the salinity component, as 
Figure 5

Schematic representation of the predicted environmental concentration profile in a compartment with (PEC) and without $\left(P E C_{i}^{0}\right)$ an imposed impulse emission

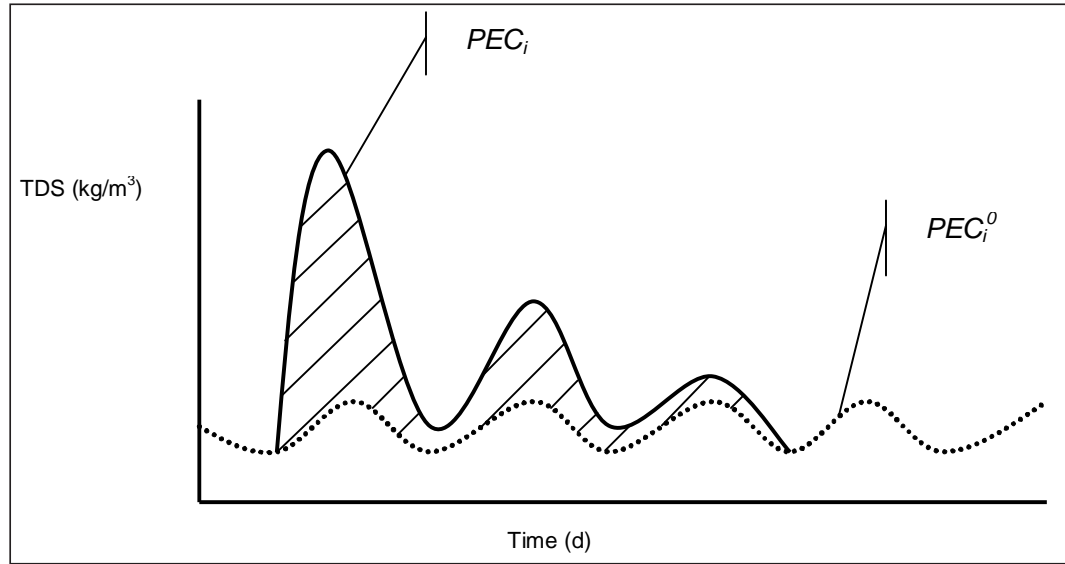

proposed by Herold (1981) be used to model salt transport. However, the following modifications to the models are proposed:

- Aerosol (and associated salt) deposition rates calculated using the atmospheric deposition model described above instead of average constant deposition rates.

- The pervious (rural) surface is divided into a rural agricultural area (on which irrigation takes place) and a natural area (on which no irrigation takes place). This will allow more accurate estimation of the salt concentration in soils supporting crops, and therefore more accurate estimation of potential salinity effects.

- An erosion and sediment transport component to be added to account for the transport of adsorbed salt. It is proposed that the model presented by Paling et al. (1989) be used as a starting point.

- Allowance to be made in the model to impose a pulse or continuous emission into any environmental compartment, at any point during the simulation, at any magnitude and for any duration.

The objective of the hydrosalinity model is therefore to calculate the dissolved salt concentration in soil moisture and surface water at a daily time-step, taking into account all possible mechanisms that influence the distribution of dissolved salts between the various environmental compartments.

The objective of the environmental fate model as a whole has to be seen in the light of the discussion on the calculation of effects potentials below.

\section{Conceptual characterisation model}

\section{Effects potentials}

In Fig. 5 a schematic representation of the predicted environmental concentration profile in a compartment with $\left(\boldsymbol{P E} \boldsymbol{C}_{\boldsymbol{i}}\right)$ and without $\left(\boldsymbol{P E C _ { i } ^ { 0 }}\right)$ an imposed impulse emission is shown. It is proposed that the same approach be adopted in calculating the equivalency factor. However, since the proposed model is not a steady-state model, it is proposed that the following general equation be used to calculate the equivalency factor:

$$
\text { Effects Potential }=\frac{\sum_{i=1}^{N}\left[P E C_{i}-P E C_{i}^{0}\right]}{P N E C M}
$$

where:

$$
\begin{aligned}
P E C_{i}= & \begin{array}{l}
\text { predicted environmental concentration }\left(\mathrm{kg} / \mathrm{m}^{3}\right) \text { in } \\
\text { the compartment during day } i \text { after an emission of }
\end{array} \\
& \text { total mass } M(\mathrm{~kg}) . \\
P E C_{i}^{0}= & \begin{array}{l}
\text { predicted environmental concentration }\left(\mathrm{kg} / \mathrm{m}^{3}\right) \text { in } \\
\text { the compartment during day } i \text { without an emission } \\
\\
\text { into the compartment. }
\end{array} \\
P N E C= & \text { predicted no-effect concentration }\left(\mathrm{kg} / \mathrm{m}^{3}\right) \\
N= & \text { number of days in the simulation. }
\end{aligned}
$$

The term "effects potential" is used rather than "equivalency factor", since the equivalency factor for salinity is made up of a number of effects potentials, as described below. It is proposed that the upper limit of the target water quality ranges given in the South African Water Quality Guidelines (DWAF, 1996) be used as no effect concentrations.

The numerator of Eq. (6) is therefore the shaded area indicated in Fig. 5. Several key principles should be mentioned regarding the results obtained from the environmental fate model and the calculation of the effects potentials:

- As the population in South Africa increases, land use practices change and urbanisation and industrialisation increase, it is likely that the concentration of dissolved salts in the water resources of South Africa will increase. It is however not necessary to include a salinity growth factor in the model, since it is logical to assume that the rate of increase in salination will be the same with and without the imposed impulse emission, and therefore the difference will be zero.

- The simulation length $(N)$ should be selected so that the difference in concentration in each environmental compartment, with and without an imposed emission impulse, is at or close to zero. This in effect means that the salinity potentials are derived for an infinite time-horizon.

In terms of the potential salinity impacts, the following effects potentials are defined for a release of salt into an initial release compartment (irc):

$$
\begin{gathered}
A E E P_{\text {irc }}=\frac{\sum_{i=1}^{N}\left[P E C_{i}^{R}-P E C_{i}^{R, 0}\right]}{P N E C_{A E} M^{R}} \\
A e E P_{\text {irc }}=\frac{\sum_{i=1}^{N}\left[P E C_{i}^{R}-P E C_{i}^{R, 0}\right]}{P N E C_{A e} M^{R}}
\end{gathered}
$$




$$
\begin{aligned}
& M D P_{\text {irc }}=\frac{\sum_{i=1}^{N}\left[P E C_{i}^{R}-P E C_{i}^{R, 0}\right]}{P N E C_{M D} M^{R}} \\
& N W E P_{\text {irc }}=\frac{\sum_{i=1}^{N}\left[P E C_{i}^{R}-P E C_{i}^{R, 0}\right]}{P N E C_{N W} M^{R}} \\
& L E P_{\text {irc }}=\frac{\sum_{i=1}^{N}\left[P E C_{i}^{R}-P E C_{i}^{R, 0}\right]}{P N E C_{L} M^{R}} \\
& N V E P_{\text {irc }}=\frac{\sum_{i=1}^{N}\left[P E C_{i}^{r n s}-P E C_{i}^{\text {rnsR }, 0}\right]}{P N E C_{N V} M^{\text {rns }}} \\
& A C E P_{\text {irc }}=\frac{\sum_{i=1}^{N}\left[P E C_{i}^{\text {ras }}-P E C_{i}^{\text {ras }, 0}\right]}{P N E C_{A C} M^{\text {ras }}}
\end{aligned}
$$

where:

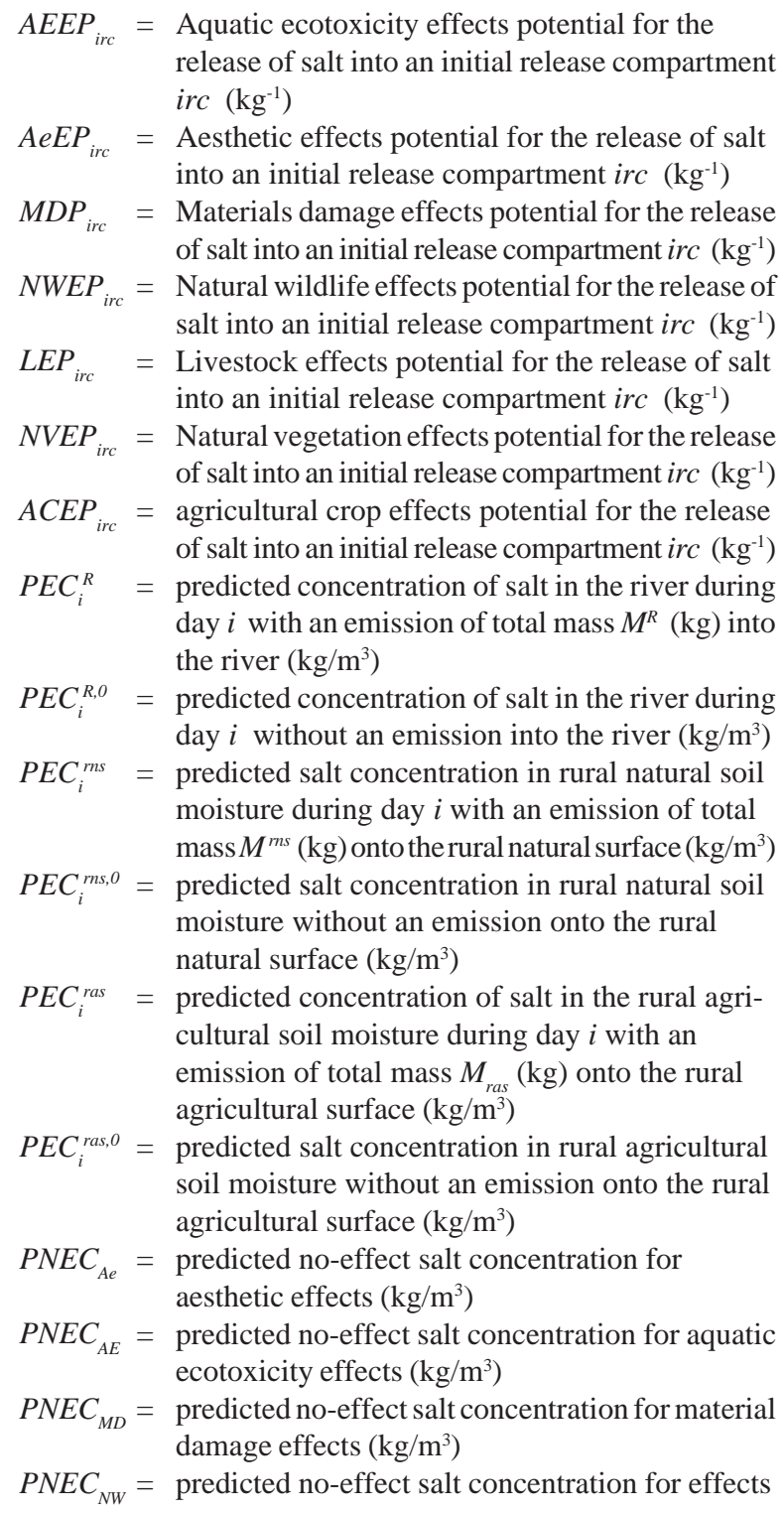

on natural wildlife $\left(\mathrm{kg} / \mathrm{m}^{3}\right)$

$P N E C_{L}=$ predicted no-effect salt concentration for effects on agricultural livestock $\left(\mathrm{kg} / \mathrm{m}^{3}\right)$

$P N E C_{N V}=$ predicted no-effect salt concentration for effects on natural vegetation $\left(\mathrm{kg} / \mathrm{m}^{3}\right)$

$P N E C_{A C}=$ predicted no-effect salt concentration for effects on agricultural crops $\left(\mathrm{kg} / \mathrm{m}^{3}\right)$

$N \quad=$ total number of days in the simulation

It can be seen from the above equations that the salt concentration in the river is used in the calculation of the aesthetic, damage, natural wildlife and agricultural livestock effects potentials. The inherent assumption is that only river water is used for domestic consumption, industrial activities, livestock watering, and by natural wildlife. In South Africa, approximately 13\% of all water used is obtained from groundwater (DWAF, 1986). The agricultural sector is the biggest user of groundwater. It is estimated that $78 \%$ of all groundwater abstracted is used for irrigation, $7 \%$ for rural purposes and 6\% for stock watering. Only $4 \%$ of the groundwater abstracted is used in the urban environment (Conrad et al., 1999).

\section{Total salinity potential}

The total salinity potential (or equivalency factor) for the release of salts into an initial release compartment (irc), can be calculated by the general formula:

$$
\begin{aligned}
T S P_{\text {irc }}= & A E E P_{\text {irc }} W_{A E E}+A e E P_{\text {irc }} W_{\text {AeE }}+M D P_{\text {irc }} W_{M D} \\
& +N W E P_{\text {irc }} W_{N W E}+L E P_{\text {irc }} W_{L E}+N V E P_{\text {irc }} W_{N V E} \\
& +A C E P_{\text {irc }} W_{A C E}
\end{aligned}
$$

where:

TSP $P_{\text {irc }}=$ total salinity potential for the release of salt into an initial release compartment irc $\left(\mathrm{kg}^{-1}\right)$

$W_{\text {AEE }} \quad=$ weighting factor for aquatic ecotoxicity effects (-)

$W_{A C E}=$ weighting factor for aesthetic effects (-)

$W_{M D}=$ weighting factor for material damage effects (-)

$W_{N W E}=$ weighting factor for natural wildlife effects (-)

$W_{L E} \quad=$ weighting factor for livestock effects (-)

$W_{N V E}=$ weighting factor for natural vegetation effects (-)

$W_{A C E}=$ weighting factor for agricultural crop effects (-)

Weighting factors (W) have been included in the calculation of effects potentials to determine the relative importance (or value) of the salinity sub-impacts listed above. For example, the calculated value of the aesthetic effects potential may be larger than the calculated value of the aquatic ecosystem effects potential, which would imply that aesthetic impacts have more environmental "value" than aquatic ecosystem effects. The value that individuals place on toxicity effects may well be higher that the value placed on aesthetic effects, and therefore allowance has been made for including weighting factors. By subcategorising the salinity impact category, therefore, value judgements would have to be made regarding the relative weighting between subcategories. This is beyond ISO, but not in conflict with ISO (Udo de Haes et al., 1999).

Human toxic effects are excluded from the above conceptual methodology for defining a salinity impact category for the following reasons:

- Toxic effects in humans due to common ions occur only at very high concentrations. Humans will, by nature, avoid the intake of highly saline water or will treat the water to acceptable salinity levels before ingestion. This is not usually the case with aquatic and terrestrial ecosystems. 
- Toxic effects by other ionic species are already accounted for in the calculation of human toxicity potentials using existing characterisation models.

\section{Conclusions and recommendations}

In Part 1 of the series, it was shown that there is sufficient justification for the creation of a separate salinity impact category. In this paper, a conceptual characterisation model is proposed for the calculation of salinity potentials, following the same approach as existing characterisation models. It is recommended that the model be developed in detail and that salinity potentials be calculated. This is the subject of Part 3 in the series.

\section{References}

CONRAD JE, COLVIN C, SILILO O, GORGENS A, WEAVER J, REINHARDTS C (1999) Assessment of the Impact of Agricultural Practices on the Quality of Groundwater Resources in South Africa. WRC Report No. 641/1/99. Water Research Commission, Pretoria. South Africa.

DE NEVERS (1995) Air Pollution Control Engineering. McGraw-Hill International Editions. Mc-Graw-Hill Book Company. Singapore.

DWA (DEPARTMENT OF WATER AFFAIRS) (1986) Managing of the Water Resources of the Republic of South Africa. Department of Water Affairs, Pretoria, South Africa.

DWAF (Department of Water Affairs and Forestry) (1996) South African Water Quality Guidelines. Vol 1 to 6. Pretoria, South Africa.

EC (1996) Technical Guidance Documents in Support of Commission Directive 93/67/EEC on risk assessment for new notified substances and Commission Regulation (EC) No. 1488/94 on risk assessment for existing substances. Part II. EC catalogue numbers CR-48-96-002. Office for Official Publications of the European Community, 2 rue Mercier, L-2965 Luxembourg.

GUINEE JB (2000) Life Cycle Assessment: An Operational Guide to the ISO Standard (Preliminary version). Centre of Environmental Science (CML). Leiden University. Leiden. The Netherlands.

GUINEE JB, GORREE M, HEIJUNGS R, HUPPES G, KLEIN R, WEGENER SLEESWIJK A and UDO DE HAES HA (2000) Life Cycle Assessment: An Operational Guide to the ISO standard (preliminary version). Centre of Environmental Science (CML). Leiden University, Leiden, The Netherlands.

GUINEE JB, HEIJUNGS R, VAN OERS L, VAN DE MEENT D, VERMEIRE T, RIKKEN M (1996) LCA Impact assessment of Toxic Releases. Generic Modelling of Fate, Exposure and Effect for Ecosystems and Human Beings with Data for about 100 Chemicals. Ministry of Housing, Spatial Planning and the Environment (VROM), Report No. 1996/21. The Hague, The Netherlands.

HEROLD CE (1981) A Model to Simulate River Flows and Associated Diffuse-Source Conservative Pollutants. Hydrological Research Unit. Report No. 3/81. University of the Witwatersrand. Johannesburg. South Africa.
HEROLD CE, TAVIV I and PITMAN WV (2001) Modelling of LongTerm Effect of Atmospheric Deposition on the Salinity of Runoff from the Klip River Catchment. WRC Report No. 697/1/01. Water Research Commission, Pretoria. South Africa.

HUGHES DA (1997) South African "FRIEND"- The Application of Rainfall-Runoff Models in the SADC Region. WRC Report No. 235/1/97. Water Research Commission, Pretoria. South Africa.

HUIJBREGTS MA (1998) Application of uncertainty and variability in LCA. Part 1. A general framework for the analysis of uncertainty and variability in life cycle assessment. Int. J. LCA 3 (5).

HUIJBREGTS MA (1999) Priority Assessment of Toxic Substances in the frame of LCA. Development and Application of the Multi-Media Fate, Exposure and Effect model USES-LCA. University of Amsterdam. Faculty of Environmental Sciences, Amsterdam, The Netherlands.

LESKE A and BUCKLEY CA (2003) towards the development of a salinity impact category for South African environmental life cycle assessments: Part 1 - A new impact category. Water SA 29 (3).

MACKAY D (1991) Multimedia Environmental Models. The Fugacity Approach. Lewis Publishers, Chelsea, USA.

MIDGLEY DC, PITMAN WV and MIDDLETON BJ (1994) Surface Water Resources of South Africa. WRC Report No. 298/1/94. Vol I to VI. Water Research Commission. Pretoria, South Africa.

PALING WAJ, STEPHENSON D and JAMES CS (1989) Modular Rainfall-Runoff and Erosion Modelling. Water Systems Research Programme Report No. 1/1989. Department of Civil Engineering. University of the Witwatersrand. Johannesburg. South Africa.

PITMAN WV (1973) A Mathematical Model for Generating River Flows from Meteorological Data in South Africa. Hydrological Research Unit. Report No. 2/73. University of the Witwatersrand. Johannesburg. South Africa.

POTTING J and HAUSCHILD M (1997a) Predicted environmental impact and expected occurrence of actual environmental impact. Part I. Spatial differentiation in life-cycle assessment via the site-dependent characterisation of environmental impact from emissions. Int. J. LCA 2 (4).

POTTING J and HAUSCHILD M (1997b) Predicted environmental impact and expected occurrence of actual environmental impact. Part II. The linear nature of environmental impact from emissions in life-cycle assessment. Int. J. LCA 2 (4).

SLEESWIJK AW and HEIJUNGS R (1996) Modelling fate for LCA. Int. J. LCA 1 (4).

SWAP R, GARSTANG M, MACKO SA, TYSON PD, MAENHAUT P, ARTAXO P, KALLBERG P and TALBOT R (1996) The long-range transport of Southern African aerosols to the tropical South Atlantic. J. Geophys. Res. 101 (D19).

VAN BEELEN P (1998) Environmental Risk Evaluation of Difficult Substances in USES 2.0. RIVM Report 679102045. RIVM. Bilthoven. The Netherlands.

UDO DE HAES HA, JOLLIET O, FINNVEDEN G, HAUSCHILD M, KREWITT W and MULLER-WENK R (1999) Best available practice regarding impact categories and category indicators in life cycle assessment. Int. J. LCA. 4 (2). 
